\title{
Recursos minerais não-metálicos
}

\author{
ARLEI BENEDITO MACEDO
}

$\mathrm{O}$ S BENS MINERAIS não-metálicos são pouco lembrados quando se fala em produção mineral no Brasil. Nenhum destes bens domina a pauta de exportação ou importação, como o ferro e o petróleo, nem tem o charme do ouro ou das pedras preciosas. Tal esquecimento não se justifica nem pelo volume ou valor de produção dos bens minerais não-metálicos, quase igual ao dos metálicos ou energéticos, nem pela importância dos não-metálicos para a economia e para o atendimento das necessidades da população.

Os bens minerais não-metálicos podem ser classificados em materiais de construção, matérias primas de fertilizantes e minerais industriais. Os materiais de construção podem ser empregados diretamente, sem industrialização, apenas com beneficiamento na mina, como os agregados para concreto (areia, cascalho, brita), ou industrializados, como calcário e argila usados em cimento, argila para cerâmica vermelha, rochas ornamentais serradas e polidas e gesso.

Para estudar a produção e a comercialização dos não-metálicos são necessários números. Os mais recentes, fornecidos pela página do DNPM (Departamento Nacional da Produção Mineral), na World Wide Web, referem-se aos anos de 1995 (Anuário Mineral de 1996, referenciado à frente como AM96) e 1996 (Sumário Mineral de 1997, a ser mencionado como SM97), cada um deles trazendo também alguns dados de dois anos anteriores ao de referência. Os dados do Anuário Mine$\mathrm{ral}$, números finais - e por isto um pouco diferentes dos preliminares apresentados pelos Sumários Minerais de 1996 e 1997 -, mais completos e abrangentes, serão geralmente utilizados para os totais. Os dados mais novos (e preliminares), usados para o estudo dos diversos setores e bens minerais abrangidos pelo Sumário Mineral, os quais não são todos os tratados no Anuário Mineral. Se isto parece confuso, o leitor não deve se desesperar: é realmente confuso, e ilustra a pequena importância dada ao setor mineral e a seus órgãos de controle pelo governo federal, o que se reflete na dificuldade de se conseguir dados. Em alguns casos foram necessários cálculos para a obtenção de índices e somas não disponíveis nas fontes. Pelos cálculos e pela seleção dos dados, a responsabilidade é do autor.

Esses números, da mesma forma que todos os oriundos do DNPM, são dados oficiais. Reúnem valores da comercialização legalizada, que pagou impostos e foi devidamente contabilizada. Conforme será explicado adiante, boa parte da produção dos bens minerais não-metálicos - e a maior parte para alguns deles, como a areia para construção civil - é produzida e consumida localmente, não pagando impostos. A produção total real é certamente muito maior que a oficialmente declarada, e deve ultrapassar o valor da produção dos outros segmentos do setor mineral, metálicos, energéticos e gemas. 
De uma Produção Mineral Brasileira (PMB) de US\$ 13.539.402.298,00 ( $A M 96)$ os bens minerais não-metálicos representavam US\$3.846.325.933,00, pouco menos que os US\$ 4.402.247.506,00 dos energéticos e os US\$ 4.054.935.696,00 dos metálicos, e muito superior aos US\$ 98.586.163,00 das gemas e diamantes. Destes totais já se pode apreciar a importância dos bens minerais não-metálicos e a injustiça do pouco interesse em considerá-los. Este menor interesse não se refere apenas aos não-metálicos. Toda a produção mineral é considerada no Brasil como não importante, do que resulta a não existência de uma política mineral e, conseqüentemente, desorganização da produção, aumento de importações, dificultando o atendimento do conjunto da economia. Embora a PMB, que expressa o valor dos bens minerais produzidos, seja relativamente pequena (aproximadamente $2 \%$ do PIB), o valor das atividades econômicas que dependem dos minerais é de aproximadamente um têrço do PIB. A alteração na produção mineral tem conseqüências diretas em grandes parcelas da economia.

A importância dos não-metálicos pode ser também apreciada quando comparada com outros bens minerais. O bem mineral metálico com maior produção, que supera largamente todos eles, é o minério de ferro - 248 milhões de toneladas em 1995. No mesmo ano foi contabilizada pelo DNPM (1996) a produção de 69 milhões de $\mathrm{m}^{3}$ de pedras britadas e 54 milhões de $\mathrm{m}^{3}$ de areia e cascalho. Considerando-se uma densidade média de 1,5 , a produção conjunta de agregados declarada naquele ano chega a 184.5 Mt, próxima daquela de minério de ferro. Ela deve ser maior, considerando-se a alta taxa de informalidade na produção de areia e cascalho. Fontes do setor consideram a produção de areia equivalente a $170 \%$ da produção de brita. Aplicando-se esta proporção a produção de areia seria de 117 milhões de $\mathrm{m}^{3}$, o que elevaria o total a 186 milhões de $\mathrm{m}^{3}$, equivalentes a 279 milhões de toneladas. Mesmo a produção de brita é considerada por alguns subdeclarada. Martins (1995) avalia tal produção anual no Brasil em 100 milhões de $\mathrm{m}^{3}$. Uma correção proporcional levaria a produção de areia a 170 milhões de $\mathrm{m}^{3}$, e o total de agregados a 270 , equivalendo a 405 milhões de toneladas, ultrapassando largamente os 248 do minério de ferro. Considerando-se a população em 160 milhões, o uso total de agregados seria de 1,15 a 2,5 toneladas por habitante/ ano, muito inferior às $6 \mathrm{t} / \mathrm{hab} / \mathrm{ano}$ da Europa Ocidental e às $10 \mathrm{t} / \mathrm{hab} / \mathrm{ano}$ dos Estados Unidos e do Canadá.

A mineração de alguns não-metálicos é extremamente lucrativa. Okagawa et al. (1986) verificaram que a mineração de areia na região metropolitana de São Paulo apresentava uma taxa interna de retorno superior a todos os outros tipos de mineração.

O destino da produção dos bens minerais não-metálicos torna-os muito importantes para o atendimento às necessidades da população. A infra-estrutura de transporte, habitação, saneamento e mesmo da produção de energia hidroelétrica baseia-se no uso de grandes quantidades de material de construção. Não devem ser esquecidos os fertilizantes minerais, fundamentais para a produção de alimentos e matérias-primas para uma crescente população, além de excedentes exportáveis. 
Os impactos ambientais causados pela lavra e beneficiamento dos não-metálicos têm extensão maior e gravidade menor que os causados pela mineração dos metálicos e energéticos. Sua gravidade é menor pois geralmente não liberam resíduos tóxicos e suas minas são menores . Entretanto, o grande número e a dispersão das minas de não-metálicos tornam o controle de seus impactos ambientais extremamente difícil.

\section{Produção, exportação e importação}

A produção dos bens minerais não-metálicos corresponde, em valor, a 31,01\% da produção mineral brasileira ( $A M 96$ ), comparável aos 32,70\% dos metálicos e $35,50 \%$ dos enérgéticos, muito maior que os $0,79 \%$ das gemas e diamantes, considerados os números oficiais. A produção real dos não-metálicos deve ser maior que a de qualquer outro subsetor.

A distribuição entre os diversos produtos é menos concentrada que a dos metálicos e energéticos. Os bens minerais que dominam o setor, em valor, são as pedras britadas $(23,17 \%$ dos não-metálicos), o calcário ( $21,95 \%)$, a areia e o cascalho $(11,95 \%)$, as argilas $(8,25 \%)$, a água mineral $(7,02 \%)$, a rocha fosfática $(5,05 \%)$, o caulim (2,98\%), o amianto (2,93\%), o granito ornamental (2,85\%), o sal marinho $(1,67 \%)$, a areia industrial $(1,22 \%)$, os sais de potássio $(1,21 \%)$ e a magnesita $(1,02 \%)$, segundo o AM96.

Alguns não-metálicos brasileiros têm importância mundial. Em reservas, de acordo com o $S M 97$, o caulim e a grafita ocupavam a segunda posição mundial em 1996, o talco e a vermiculita o terceiro, a magnesita o quinto, com a fluorita e as rochas fosfáticas no sexto. Em produção o caulim ocupava o terceiro lugar mundial, a vermiculita e a grafita o quarto, a magnesita e o talco o quinto, e os fosfatados o oitavo lugar.

Nas tabelas 1 e 2 são mostradas essas posições e incluídas também a posição dos bens minerais metálicos.

Em 1996 o comércio exterior de bens minerais do Brasil registrou exportação no valor de US\$ 11,3 bilhões e importação de US\$ 10,9 bilhões com um saldo de US\$ 400 milhões, inferior ao do ano anterior, que foi de US\$ 1,529 bilhões e ao de 1994, de US\$2,739 bilhões. De 1994 para 1995 houve aumento de 7,31\% no valor das exportações e de $25,84 \%$ nas importações. De 1995 para 1996 houve diminuição no valor das exportações (12\%) e aumento (8\%) nas importações, atribuídos pelo $S M 97$ à redução tarifária.

A exportação de bens minerais não-metálicos em 1995 foi de US\$ 1.189 milhões, e a importação de US\$ 1.503, com um saldo negativo de US\$ 314 milhões (AM96). Não são disponíveis os dados divididos por grupos de substâncias para 1996.

Na tabela 3 é comparado o desempenho dos grupos de substâncias e graus de industrialização em 1995. 
Tabela 1

Posição do Brasil nas reservas mundiais de bens minerais

\begin{tabular}{lll}
\hline Mineral & Posição & Part.\% \\
\hline Nióbio & $1^{0}$ & 88,1 \\
Caulim & $2^{0}$ & 12,7 \\
Grafita & & 12,8 \\
Bauxita & $3^{\circ}$ & 19,0 \\
Talco & & 19,0 \\
Vermiculita & & 8,3 \\
Magnesita & $5^{0}$ & 5,2 \\
Manganês & $6^{0}$ & 1,0 \\
Fosfatados & & 1,1 \\
Fluorita & & 2,5 \\
Estanho & & 9,5 \\
Ferro & & 8,6 \\
Cromo & & 1,2 \\
Zinco & $7^{0}$ & 1,7 \\
\hline Fonte:
\end{tabular}

Fonte: Sumário Mineral, 1997 (DNPM, 1997).

Tabela 2

Posição do Brasil na produção mundial de bens minerais

\begin{tabular}{lll}
\hline Mineral & Posição & Part.\% \\
\hline Nióbio & $1^{0}$ & 90,0 \\
Ferro & & 18,3 \\
Manganês & $2^{0}$ & 14,8 \\
Bauxita & $3^{0}$ & 10,8 \\
Caulim & & 5,5 \\
Estanho & $4^{0}$ & 9,5 \\
Vermiculita & & 4,2 \\
Grafita & & 5,0 \\
Magnesita & $5^{\circ}$ & 10,5 \\
Talco & & 8,0 \\
Zinco & $7^{0}$ & 1,6 \\
Cromo & & 3,7 \\
Fosfatados & $8^{0}$ & 2,9 \\
\hline
\end{tabular}

Fonte: Sumário Mineral, 1997 (DNPM, 1997) 
Tabela 3

Comércio exterior de bens minerais do Brasil, dividido por setor (unidade US\$ mil)

\begin{tabular}{lcrrrrr}
\hline Exportação & Primários & $\begin{array}{c}\text { Semi- } \\
\text { manufaturados }\end{array}$ & Manufaturados & $\begin{array}{c}\text { Compostos } \\
\text { químicos }\end{array}$ & Totais & Saldos \\
\hline Total & 3083680 & 4178151 & 3328818 & 257418 & 10848067 & 1401748 \\
Metálicos & 2754198 & 4032176 & 2174080 & 93305 & 9053759 & 6910103 \\
Não-metálicos & 214021 & 145970 & 708500 & 120578 & 1189069 & -314759 \\
Gemas e diam. & 60441 & 0 & 85845 & 0 & 146286 & 132437 \\
Energéticos & 55020 & 5 & 360393 & 43535 & 458953 & -5726033 \\
\hline & & & & & \\
Importação & Primários & Semi- & Manufaturados & Compostos & & \\
\hline Total & 4359454 & 594165 & 3427194 & 1065506 & 9446319 & \\
Metálicos & 476583 & 592255 & 720437 & 354381 & 2143656 & \\
Não-metálicos & 502069 & 1882 & 508068 & 491809 & 1503828 & \\
Gemas e diam. & 6363 & 0 & 7486 & 0 & 13849 & \\
Energéticos & 3374439 & 28 & 2591203 & 219316 & 6184986 & \\
\hline
\end{tabular}

Fonte: Anuário Mineral Brasileiro, 1996 
Tabela 4 - Exportação mineral brasileira - 1994-1996

(Principais substâncias - não-metálicos) Unid.: US\$ mil-FOB

\begin{tabular}{|c|c|c|c|c|}
\hline \multirow[b]{2}{*}{ Substância } & \multicolumn{4}{|c|}{ Total } \\
\hline & 1993 & 1994 & 1995 & 1996 \\
\hline Água mineral & 788 & 207 & 213 & 204 \\
\hline Amianto & 73.300 & 67.669 & 73.445 & 82.962 \\
\hline Barita & 2.497 & 2.351 & 1.972 & 2.864 \\
\hline Bentonita & 73 & 132 & 178 & 66 \\
\hline Cal & 567 & 247 & 1.662 & 0 \\
\hline Caulim & 61.014 & 51.711 & 57.229 & 78.870 \\
\hline Cimento & 10.243 & 9.091 & 12.842 & 0 \\
\hline Diatomita & 29 & 53 & 148 & 459 \\
\hline Enxofre & 63 & 26 & 190 & 179 \\
\hline Feldspato & 187 & 87 & 13 & 9 \\
\hline Fert. Fosf. & 19.841 & 20.806 & 28.036 & 26.009 \\
\hline Fluorita & 199 & 169 & 176 & 112 \\
\hline Gipsita & 551 & 410 & 560 & 688 \\
\hline Grafita & 10.281 & 10.403 & 11.871 & 57.107 \\
\hline Magnesita & 29.041 & 15.215 & 21.820 & 41.544 \\
\hline Mica & 2.198 & 3.114 & 2.551 & 2.952 \\
\hline Sais de potássio & 778 & 500 & 227 & 33.680 \\
\hline Quartzo (Cristal) & 7.079 & 6.826 & 10.976 & 10.896 \\
\hline Rochas ornamentais & 94.907 & 122.786 & 136.148 & 152.599 \\
\hline Sal & 2.706 & 3.603 & 2.096 & 2.290 \\
\hline Talco & 488 & 571 & 793 & 506 \\
\hline Vermiculita & 732 & 855 & 293 & 3.374 \\
\hline
\end{tabular}

Fontes: Sumário Mineral, 1996 e 1997 
Tabela 5 - Importação mineral brasileira - 1994-1996

(Principais substâncias - não-metálicos) Unid.: US\$ mil-FOB

\begin{tabular}{|c|c|c|c|c|}
\hline \multirow[b]{2}{*}{ Substância } & \multicolumn{4}{|c|}{ Total } \\
\hline & 1993 & 1994 & 1995 & 1996 \\
\hline Água mineral & 134 & 482 & 989 & 904 \\
\hline Amianto & 25.343 & 28.649 & 41.010 & 34.115 \\
\hline Barita & 1.593 & 815 & 1.140 & 227 \\
\hline Bentonita & 9.188 & 7.170 & 13.889 & 7.241 \\
\hline Cal & 146 & 74 & 248 & 64 \\
\hline Caulim & 780 & 927 & 1.012 & 12.760 \\
\hline Cimento & 11.009 & 34.321 & 36.138 & 0 \\
\hline Diatomita & 1.987 & 1.089 & 2.225 & 2.035 \\
\hline Enxofre & 59.040 & 113.191 & 61.864 & 0 \\
\hline Feldspato & 80 & 53 & 1.329 & 320 \\
\hline Fluorita & 296 & 3 & 1.683 & 1.370 \\
\hline Fert. fosfát. & 199.673 & 297.402 & 268.346 & 35.732 \\
\hline Gipsita & 272 & 725 & 2.606 & 2.254 \\
\hline Grafita & 196 & 237 & 1.942 & 90.732 \\
\hline Magnesita & 6.755 & 6.983 & 9.343 & 30.508 \\
\hline Mica (Moscovita) & 1.928 & 1.840 & 2.340 & 1.307 \\
\hline Sais de potássio & 308.025 & 329.011 & 371.008 & 40.491 \\
\hline Quartzo (Cristal) & 13.745 & 11.741 & 18.475 & 21.956 \\
\hline Rochas ornamentais & 2.615 & 6.756 & 22.565 & 21.569 \\
\hline Sal & 810 & 531 & 1.661 & 1.593 \\
\hline Talco & 571 & 842 & 1.650 & 2.521 \\
\hline
\end{tabular}

Fontes: Sumário Mineral 1996 e 1997 (DNPM, 1996 e 1997) 


\section{Desempenho de produção e impacto ambiental da mineração dos não-metálicos}

\section{Materiais de construção}

Os bens minerais usados em construção civil - nas formas bruta e industrializada - representam o maior volume e valor de produção dos não-metálicos e, em seu conjunto, empregam mais mão-de-obra do que qualquer dos outros grupos do setor mineral. Em 1995, dos 75.372 trabalhadores, em todos os níveis, registrados nas minas e usinas de beneficiamento brasileiras, $40 \%$ pertenciam ao subsetor de materiais de construção (incluindo cimento), 15,9\% aos outros não-metálicos, 37,9\% ao subsetor de metálicos, $6 \%$ aos energéticos sólidos (carvão e turfa) e $1,2 \%$ às gemas (AM97).

Esses números são os declarados nos Relatórios Anuais de Lavra, não levando em conta os trabalhadores dos garimpos e das minas não-legalizadas - que são maioria em quase todos os estados - para o aproveitamento de areia, cascalho, concreções usadas como cascalho, pedra de alvenaria e argila para olarias e pequenas cerâmicas. Mesmo em setores organizados, como o das rochas ornamentais, é comum a extração ser feita por empreiteiros, que recebem por $\mathrm{m}^{3}$ produzido, e mantêm relações informais com as companhias detentoras dos direitos minerários e com seus trabalhadores. Das pedras assim produzidas, a parcela destinada ao mercado interno é apenas parcialmente declarada. Em algumas áreas ainda é feita britagem manual, com famílias inteiras quebrando pedras com martelos, recebendo por metro cúbico produzido, sem qualquer assistência ou direito trabalhista e, evidentemente, sem declaração ao DNPM ou pagamento de impostos.

O autor considera, juntamente com outros profissionais do setor mineral, que os trabalhadores informais na mineração dos não-metálicos superam aqueles empenhados em todos os outros setores, acreditando fantasiosas e infundadas as declarações dos líderes garimpeiros, que contam em centenas de milhares os trabalhadores do garimpo. Embora estes fossem em grande número no início da década, a maioria mudou de atividade com a redução dos preços do ouro e da cassiterita, que tornou inviáveis quase todas as lavras, restando apenas as altamente mecanizadas ou seu extremo, os requeiros que sobrevivem em áreas abastecidas a baixo custo, como na zona urbana de Poconé, MT.

A produção dos bens minerais usados em construção constitui pelo menos $68,17 \%$ do subsetor dos não-metálicos, aproximadamente $20 \%$ da produção mineral brasileira, segundo o $A M 97$. Considerando a informalidade que domina a produção de alguns de seus bens minerais, é muito provável que a sua participação seja bem maior, embora pequena no comércio exterior, destacando-se apenas a das rochas ornamentais.

São poucos os levantamentos confiáveis sobre a produção de materiais de construção e particularmente difícil quantificar a produção de areia. Bauermeister (1996) mostrou a grande discrepância dos levantamentos até a data, e calculou, a 
partir de visita a quase todos os produtores, ser a região metropolitana de São Paulo abastecida por 225 portos de areia, que para lá enviavam $12.887 .040 \mathrm{~m}^{3}$ de areia por ano, significando aproximadamente $0,7 \mathrm{~m}^{3} /$ habitante/ano. Dessa produção, apenas $25 \%$ vinham da própria região, evidenciando que a maior parte da areia tinha de ser transportada de outras áreas, algumas situadas a até $250 \mathrm{~km}$ do ponto de utilização. A produção de materiais de construção teria de ser bem maior para que fossem atendidas as necessidades de infra-estrutura e habitação, precárias na maior parte do país. Como já visto, a produção total brasileira de agregados é avaliada de 123 a 270 milhões de $\mathrm{m}^{3}$, equivalendo a aproximadamente 0,7 a 1,7 $\mathrm{m}^{3} / \mathrm{hab} / \mathrm{ano}$, bem menor do que a de países desenvolvidos, e muito menor do que a exigida para atender minimamente às necessidades da população.

A produção brasileira de rochas ornamentais e de revestimento em 1996 foi de 2.038.597 t, 751.000 t das quais exportadas, a maioria em bruto, com apenas $51.000 \mathrm{t}$ de rochas processadas. Ao mesmo tempo, as importações cresceram para $43.230 \mathrm{t}$, sendo apenas $2.860 \mathrm{t}$ não-processadas. $\mathrm{O}$ total em valor exportado foi de US\$ 152.599,00 e o importado US\$21.569,00 (DNPM, 1997).

A área de rochas ornamentais demonstra bem as características de produção mineral subdesenvolvida. Baseia-se em grande parte na extração de blocos com técnica rudimentar, exporta principalmente blocos de matéria prima, num mercado controlado por grandes companhias multinacionais, que em alguns casos processam as rochas brasileiras - principalmente na Itália - e exportam o produto acabado. A redução tarifária para máquinas de processamento de pedras não gerou um explosivo aumento da exportação de materiais acabados, como era a expectativa declarada dos produtores, o que denota o aproveitamento inadequado de vantagens comparativas, principalmente a grande quantidade e variedade das reservas do país.

Os bens minerais usados em construção são responsáveis pela maior extensão de impactos ambientais de mineração no Brasil. Embora individualmente sejam quase sempre pequenas, as lavras de materiais de construção estão em toda parte e, em muitos casos, seu controle ambiental é nulo. Sempre ocorre o impacto visual das áreas escavadas, que com as chuvas contribuem com sedimentos para a turbidez das águas e o assoreamento dos cursos d'água. Pedreiras usam explosivos, e nem sempre o ruído, as vibrações e o ultralançamento dos fragmentos são controlados. Lavras em leitos de rios avançam sobre suas margens, mudando seu curso. Após a lavra restam buracos, paredes de pedra verticais e alterações no fluxo e na qualidade das águas superficiais e subterrâneas. Os granitos para rochas ornamentais são lavrados geralmente em matacões, com aproveitamento de pequena parte do material disponível. Apenas em áreas muito próximas de grandes cidades, principalmente na região metropolitana de São Paulo, há aproveitamento dos rejeitos dos blocos para paralelepípedos e outras formas de pedra de alvenaria.

A lavra de materiais de construção exprime - melhor que qualquer outra - a variedade das condições tecnológicas e sociais da mineração no Brasil. Apenas peque- 
no número de pedreiras, portos de areia e lavras de calcário para cimento usam tecnologia moderna de extração e beneficiamento e efetuam controle ambiental durante e após a operação; tais minas, em geral, convivem com a informalidade legal e o primitivismo tecnológico da maioria das pequenas operações.

Areia e brita têm valor baixo e alto volume de produção. Elevada proporção do custo até o consumidor final deriva do frete, obrigando à produção próxima aos locais de utilização, dentro ou a pouca distância das áreas urbanas. Essa necessidade acarreta a interferência entre a mineração e os outros usos de solo urbano e suburbano, gerando conflitos, em geral mal administrados no Brasil. As áreas mal lavradas ficam impróprias a outra utilização; pedreiras são envolvidas pela urbanização e, depois, expulsas pela população envolvente, atingida pelos impactos da lavra. É necessário o planejamento do uso do solo, para garantir a possibilidade de minerar os recursos necessários à edificação da cidade; ao mesmo tempo, é preciso controlar os impactos e garantir a recuperação das áreas mineradas, para que sejam novamente utilizadas. Como veremos, uma parte da legislação existe: a que controla e restringe a mineração, geralmente mal aplicada. Quase nunca a mineração é incluída nos planos municipais, nem são garantidas áreas para seu exercício, mesmo em regiões de alto potencial e produção. Macedo et al. (1985) verificaram o avanço da urbanização na região metropolitana de São Paulo sobre as áreas com depósitos lavráveis de areia; mesmo com o total conhecimento dos órgãos de planejamento municipal e metropolitano que participavam do projeto, o avanço continuou sem qualquer providência. Das áreas identificadas por Macedo et al. (1986) como adequadas à mineração de areia, muitas foram inviabilizadas nos anos seguintes por loteamentos, em grande parte, irregulares (Bauermeister, 1996).

Outro exemplo da inviabilização de áreas para mineração refere-se à diferença entre os recursos de areia identificados por Francisconi et al. (1994) e Bauermeister (1996). O primeiro trabalho considerou um volume de recursos de 1.595.900.000 $\mathrm{m}^{3}$ de areia dentro da região metropolitana de São Paulo. Caso fossem lavráveis, abasteceriam a região por aproximadamente 100 anos. No entanto, o segundo trabalho apontou apenas 246,654 milhões $\mathrm{de}^{3}$, dos quais 75 milhões em áreas com restrições de ordem legal ou ambiental não-proibitivas. A diferença entre os recursos identificados nos dois estudos encontra-se em áreas inviabilizadas por usos permanentes ou por restrições de ordem legal ou ambiental irremovíveis.

Algumas iniciativas aparecem no sentido de aumentar a sustentabilidade do setor, a exemplo do aproveitamento de rejeitos de construção e pó de pedra como agregados e as propostas de combinar o desassoreamento de rios - como o Tietê com a produção de areia. Embora tendo de resolver os problemas tecnológicos da limpeza da areia, que vem misturada com argila, poluída por resíduos tóxicos industriais e esgotos domésticos, o tratamento dos sedimentos do rio Tietê, na região metropolitana de São Paulo, é considerado possível e lucrativo, transformando o que é atualmente uma despesa para as prefeituras numa fonte de renda (Casadei et al., 1997). Além disso, a areia produzida dentro de São Paulo não precisa ser transportada de longe, poupando o custo do frete e os inconvenientes do transpor- 
te por caminhões, principalmente o congestionamento das rodovias e os constantes acidentes.

\section{Fertilizantes}

O Brasil produziu 3,8 milhões de toneladas de rocha fosfática em 1996 (SM 97), ocupando a oitava colocação no mundo, enquanto suas reservas lhe garantem a sexta. Mesmo assim teve de importar US\$ 432 milhões de matérias primas para fertilizantes fosfáticos, exportando US\$ 34 milhões. Assim, são atendidas pela produção nacional $79 \%$ das necessidades de rocha fosfática, $81 \%$ das de ácido fosfórico e $78 \%$ de produtos intermediários.

Em sais de potássio a situação é pior. A produção nacional atende apenas a $12 \%$ do consumo, obrigando à importação de US\$ 1,809 milhões, não-compensada pela exportação de US\$ 401 milhões em 1996 ( SM97). A produção (em toneladas equivalentes a $\mathrm{K}_{2} \mathrm{O}$ ) foi de $234.265 \mathrm{t}$, insuficiente para um consumo aparente de 1.898 .894 t, em sua maior parte atendido pela importação.

Os fertilizantes nitrogenados, classificados entre os energéticos por serem produzidos pela indústria petroquímica, são aqui incluídos para completar a análise dos principais fertilizantes. Em 1995 (AM96) foram exportados US\$ 45,535 milhões de uréia, US\$ 19,996 milhões de amônia anidra e US\$ 2,672 milhões de nitrato de amônio, enquanto importados US\$ 70,768 milhões de uréia, US\$ 66,891 milhões de amônia anidra e US\$ 5,756 milhões de nitrato de amônio.

Essa dependência externa em fertilizantes é inquietadora. O Brasil não alimenta convenientemente grande parte de sua população. Para o atendimento de suas necessidades alimentares mínimas haveria necessidade de aumentar a produção de alimentos (e o uso de fertilizantes) ou agravar ainda mais as contas externas. Além disso, uma das poucas saídas apontadas para minimizar a exclusão social de grande parte da população é a reforma agrária em grande escala, que aumentaria ainda mais a demanda de fertilizantes. Duas soluções podem ser sugeridas: aumentar a produção de fertilizantes, investindo na mineração e na industrialização, e melhorar o sistema de treinamento e extensão agrícola, visando ao uso mais eficiente dos fertilizantes químicos, complementado por práticas de agricultura orgânica - muito eficientes em pequenas propriedades - caso das resultantes da reforma agrária.

O impacto ambiental da produção de fertilizantes fosfáticos é pequena, pois as minas são poucas e seu impacto bem controlado. Os sais de potássio são lavrados por dissolução in situ, no depósito, em profundidade e bombeados para a superfície, causando impacto ambiental quase nulo. A produção dos nitrogenados está associada aos complexos petroquímicos, causando impacto do tipo industrial, atualmente bem controlado no Brasil.

O maior impacto dos fertilizantes, tanto no Brasil quanto no mundo, está em seu uso, principalmente no dos nitrogenados. Em alguns casos foram aplicadas quantidades maiores que a necessária, principalmente em época na qual havia ge- 
nerosos subsídios para sua compra. A aplicação muitas vezes é feita sem um estudo técnico da associação planta-solo-fertilizante, procedimento que além de causar desperdício, polui as águas superficiais e subterrâneas.

Um esforço na aplicação correta de fertilizantes deveria ser um dos componentes fundamentais para o desenvolvimento sustentável da agricultura. As técnicas já existem. O uso de fertilizantes fosfáticos parcialmente solubilizados ou a aplicação direta de rochas fosfáticas reduz a perda por dissolução; a compostagem e a elaboração de fertilizantes organo-minerais maximizam o aproveitamento dos nutrientes; o uso da adubação verde para a captação de nitrogênio atmosférico e para aproveitamento dos resíduos de fertilizantes de culturas anteriores, além da cobertura do solo evitando a decomposição acelerada da matéria orgânica, também é procedimento técnica e economicamente viável. Faltam, entretanto, educação, extensão rural e política de crédito que favoreçam a produção sustentável, e não o uso indiscriminado de insumos como já foi regra neste país.

\section{Minerais industriais}

O Brasil é fornecedor externo de bens minerais que constituem matéria prima para as indústrias química e metalúrgica (nesta, de forma subsidiária), chamados minerais industriais. É o terceiro produtor mundial de caulim, quarto de vermiculita e grafita, quinto de magnesita e talco. Também tem balanço positivo em amianto e barita. No entanto, esta área também tem sido atingida por facilidades tarifárias e de financiamento de importações, notando-se o grande aumento de importações da grafita em 1996 (para US\$ 90 milhões, a partir de US\$ 196 mil em 1993), revertendo assim a balança tradicionalmente favorável ao país para este bem mineral.

Trata-se de uma área complexa. As necessidades da indústria flutuam muito, e os volumes e preços são influenciados pela substituição por novos materiais e processos, como no caso do quartzo, em que os cristais de grande pureza e tamanho podem ser substituídos por areia, abundante e ubíqua. A política mineral aqui deve seguir de perto a política industrial, orientando investimentos para áreas com potencial de lucratividade a médio prazo e não seguindo a penúltima moda, como já foi regra em nossa política mineral.

\section{Política minerária e ambiental dos não-metálicos}

A Constituição Federal de 1988, em seu artigo 20, declara os bens minerais bens da União, sendo seu aproveitamento por particulares dependente de concessão (art. 176). A forma do aproveitamento é definida pelo Código de Mineração (Decreto-Lei n ${ }^{\circ} 227$, de $27 / 2 / 67$, muito alterado pela Lei n ${ }^{\circ} 9.314$, de 14/11/96). Nele são especificados os regimes de autorização e concessão, complementares, $\mathrm{o}$ de licenciamento e o de garimpagem, este último pouco usado para não-metálicos.

Os bens de uso imediato em construção civil são considerados bens minerais de uso social pela sua importância no atendimento das necessidades diretas da po- 
pulação, tanto individualmente, pela construção residencial, quanto por constituírem a quase totalidade dos materiais empregados na infra-estrutura urbana e de transportes. Por esse motivo são favorecidos pela legislação, que oferece a possibilidade de opção pelo regime de licenciamento, simplificado, embora menos seguro que o de autorização e concessão por exigir renovação periódica da licença.

A proteção ao meio ambiente durante a mineração é exigida primeiramente pela Constituição Federal, que em seu Artigo 225 declara: "Todos têm direito ao meio ambiente ecologicamente equilibrado, ...” e especifica:

"Parágrafo $1^{\circ}$ : Para assegurar a efetividade desse direito, incumbe ao Poder Público:

IV - exigir, na forma da lei, para instalação de obra ou atividade potencialmente causadora de significativa degradação do meio ambiente, estudo prévio de impacto ambiental, a que se dará publicidade

Parágrafo $2^{\circ}$ : Aquele que explorar recursos minerais fica obrigado a recuperar o meio ambiente degradado, de acordo com solução técnica exigida pelo órgão público competente, na forma da lei”.

Este parágrafo é regulamentado pelo Decreto $\mathrm{n}^{\circ}$ 99.274, de 6/6/90.

A proteção ambiental é especificada na Política Nacional do Meio Ambiente (Lei n ${ }^{\circ}$ 6938, alterada pelas Leis 7804 e 8028 e regulamentada pelo Decreto 99.274) e o Estudo de Impacto sobre o Meio Ambiente é exigido pela Resolução n ${ }^{\circ} 001$ do Conama, de 23/1/86).

Ao se observar tais números, datas e modificações deles constantes, já se começa a intuir que a legislação ambiental e minerária no Brasil constitui parte do problema, e não a sua solução. A realidade é muito pior.

Em primeiro lugar, a legislação é muito mais intrincada, com leis, decretos, resoluções, portarias, instruções etc. em grande número, uns alterando outros, sem que no tradicional "revoguem-se as disposições em contrário" sejam indicadas quais as que realmente serão revogadas.

Coisas fundamentais, como a regulamentação do artigo 23 da Constituição Federal, não são feitas. Este especifica:

“É da competência comum da União, dos Estados, do DF e dos municípios:

VI - proteger o meio ambiente e combater a poluição em qualquer de suas formas;

XI - registrar, acompanhar e fiscalizar as concessões de direitos de pesquisa e exploração de recursos hídricos e minerais em seus territórios."

Assim, a participação das diversas esferas de governo é mal definida, não impedindo que o furor legisferante ataque de tempos em tempos os estados e municípios, que assim fazem sua parte para aumentar a confusão. 
Em segundo lugar, a aplicação da lei é extremamente falha. Embora o Departamento Nacional da Produção Mineral tenha sido recentemente instituído como Autarquia (Decreto ${ }^{\circ} 1.324$, de $2 / 12 / 94$ ), continua sem recursos - materiais ou humanos - e sem apoio político para cumprir minimamente sua função. Grande parte de seu pessoal mereceria melhor sorte, e tem se empenhado em fazer o possível com o pouco disponível. Deve-se elogiar a informatização, ainda lenta, mas que permite o acesso à legislação e às estatísticas (e acesso parcial a outros dados), pela página da World Wide Web, com endereço http://www.dnpm.gov.br

As outras funções governamentais com relação à mineração estão em pior estado. A fiscalização do patrimônio mineral e das condições ambientais da mineração, atribuição também do DNPM, é extremamente falha. Os levantamentos geológicos são executados em ritmo muito lento pela CPRM (Serviço Geológico do Brasil), também atingida pela falta e irregularidade de recursos.

$\mathrm{Na}$ área ambiental, a fiscalização da mineração também é atribuição dos órgãos de controle ambiental do Ministério do Meio Ambiente e das secretarias estaduais. Em alguns exemplos, irregulares no tempo e no espaço, há esforços efetivos de fiscalização, controle, pesquisa e apoio aos produtores. Mudam os governos ou aumentam as pressões dos poluidores e os trabalhos são descontinuados, equipes dispersas, recursos evaporados.

Mesmo nas raras ocasiões em que os diversos agentes cumprem suas funções, falta coordenação entre suas ações. Reivindicação antiga dos mineradores e também dos técnicos dos órgãos de controle refere-se ao denominado guichê único: um local onde o proponente de um projeto possa receber as informações necessárias para a sua legalização e, lá mesmo, entregar seus documentos para serem analisados por uma equipe mista, com funcionários dos diversos órgãos com atribuição no setor. Embora já tenham sido formalizados convênios entre algumas instituições (como DNPM-Emplasa, DNPM-SMA), isso nunca ocorreu. O número de instituições que têm ou julgam ter atribuição sobre a mineração é assustador. Em estudo feito pelo CREA sobre mineração de areia foram identificadas 18 diferentes instituições relacionadas com a mineração em leito de rio na região metropolitana de São Paulo, número menor que as 26 do Colorado (Macedo, 1995), mas que prejudica quem queira minerar dentro da lei.

Nesse ambiente inseguro, parte das ações de fiscalização acabam sendo feitas pelo Ministério Público e por ONGs, usando a Lei da Ação Civil Pública (nº 7347 de 24/7/85). Em alguns casos, pelo menos, tais ações parecem ter mais efeito de intimidação e aumento de custos para mineradores que tentam cumprir os regulamentos do que de efetivo controle ambiental (Macedo, 1995). A não-universalização da prática de colocar a ONG denunciante como parte impede que lhe seja exigido o pagamento de custas e honorários advocatícios, em caso de ser a denúncia infundada, ou o décuplo das custas, no caso de má fé, como determina a lei. Assim, a denúncia infundada é favorecida, com o apoio da não-obrigatoriedade de vistoria técnica antes da proposição da ação, mesmo nos casos em que é pedida liminar. 
Esta pode ser concedida e uma mineração paralisada, sem que esteja cometendo crime. Até que a situação se esclareça, o que no Brasil pode ser muito demorado, a mineração continuará fechada. O inverso também acontece. Em casos de manifesto crime ecológico é possível a um réu mal intencionado e bem assessorado arrastar um processo por anos, sem pagar multas nem recuperar a área degradada (Macedo et al., 1997).

Os municípios, que têm a atribuição de gerir o patrimônio mineral no que se refere ao licenciamento para lavra de bens minerais de uso direto em construção civil, além de seus deveres na ordenação do uso do solo e da defesa do meio ambiente, na maioria dos casos não estão equipados nem dão importância à mineração. Exceto por honrosas exceções - também irregulares no tempo e no espaço - de capitais, municípios de regiões metropolitanas e de áreas como o Vale do Paraíba, a mineração não é prevista como uso do solo nem regulamentada. Somente existe ação municipal para proibir a mineração nos casos em que os conflitos e interferências no uso do solo se tornam insolúveis. As proibições são levantadas quando se nota o fato óbvio de ser pior ter de comprar material de construção em outros municípios do que controlar a mineração desses bens em seus próprios territórios. Mesmo assim, raramente os conflitos levam a legislações abrangentes. São tratados caso a caso, com as soluções flutuando conforme as pressões políticas e econômicas.

Em síntese, ocorre no Brasil uma situação contraditória. É fácil fazer mineração criminosa, tanto do ponto de vista do patrimônio mineral que é aproveitado sem a devida concessão e, na maioria dos casos, sem a aplicação da devida técnica, quanto do ponto de vista ambiental, conforme testemunham os buracos em todas as partes do país. Ao mesmo tempo, para o minerador que quer cumprir os regulamentos, é tudo difícil, começando por saber quais os regulamentos a serem cumpridos. Ele necessita obter autorizações e licenças de órgãos federais, estaduais e municipais, cujos pedidos demoram até anos para ser apreciados. Mesmo uma concessão não lhe dá garantia. Sua área pode ser invadida por garimpeiros, sem que o Estado lhe garanta os direitos ou, mesmo, sua incolumidade física. Pode sofrer multas ou fechamento, com custos e dificuldade de defesa, mesmo operando dentro da lei. Seus custos serão conseqüentemente maiores do que os de seus concorrentes não legalizados.

Não é de se admirar não ter ocorrido aqui o tão decantado boom de investimentos, esperado após a queda da proibição da mineração por empresas estrangeiras. Ao indagar geólogos que assessoram investidores em mineração dos Estados Unidos sobre o não-investimento no Brasil - mesmo com sua reconhecida potencialidade para jazidas de alto tamanho e teor -, os principais motivos apontados ao autor foram: insegurança na posse das jazidas, legislação restritiva (agora amenizada), dificuldades burocráticas e falta de dados básicos confiáveis em escalas adequadas para prospecção. Para os investidores nacionais, escaldados em tantos planos e pacotes salvadores, torna-se difícil optar por um investimento de longo prazo, especialmente com as taxas de juros atuais, que tornam negativos os valores atuais líquidos de quase todas as análises de investimentos (o que significa que é 
mais lucrativo deixar o dinheiro em aplicações improdutivas de renda fixa que aplicá-lo à produção).

\section{Conclusões}

Será possível melhorar a produção mineral brasileira ?

Em primeiro lugar é imprescindível fixar objetivos. É necessário aumentar a produção para atender às necessidades da população e, nos casos em que há vantagens comparativas, aumentar as exportações. Entretanto, o aumento desordenado da produção, sem controle ou recuperação ambiental, não é desejável.

Deve-se visar ao desenvolvimento sustentável em mineração, por mais difícil que seja aplicar este conceito a recursos não-renováveis. Aplicando-se a definição clássica (atender às necessidades do presente sem comprometer a capacidade das gerações futuras atenderem às suas), a sustentabilidade na mineração é impossível, pois qualquer utilização de bens minerais reduz a base de recursos (totalidade do bem mineral existente), pois os bens minerais não são renováveis. Segundo Daly (1991), a sustentabilidade dos não-renováveis é alcançada quando seu consumo é igual ou menor que a geração de substitutos e, ao mesmo tempo, é controlado o problema dos resíduos produzidos por suas produção e utilização.

As diretrizes internacionais não ajudam muito. $\mathrm{O}$ autor analisou a Agenda 21 com relação à degradação da terra sólida (Macedo, 1997b) e constatou: em primeiro lugar, a mineração é quase ignorada naquele extenso documento. É raramente citada, e quase sempre como agente poluidor. Pouco se fala sobre seu papel no fornecimento de matérias primas para assegurar a vida humana na Terra. Repete-se aqui, em nível internacional, e entre os ambientalistas, a mistura de ignorância e desprezo pela mineração que aparece na política brasileira. Em segundo lugar, a Agenda especifica numerosas medidas institucionais e organizacionais para a implementação de medidas de desenvolvimento sustentável. Além da ausência da mineração, aparece a incoerência básica da Agenda: enquanto em muitos pontos é preconizada a iniciativa local, muitas medidas são propostas em extremo detalhe, com prazos precisos (que agora se revelam não-cumpridos), tornando impossível cumprir esses pormenores e ter alguma iniciativa local. $\mathrm{O}$ melhor seria estabelecer os princípios básicos para que fossem tomadas as medidas possíveis a cada local.

O desenvolvimento sustentável em mineração não depende apenas do setor mineral. As medidas mais eficientes para a redução do esgotamento de recursos e do impacto ambiental da mineração são as destinadas a diminuir o uso de bens minerais. A produção de bens de consumo mais duráveis, a reutilização e a reciclagem, a racionalização do uso, como já exemplificado para fertilizantes, bem como a substituição por recursos renováveis, têm efeito maior que as ações dentro do setor mineral para a sustentabilidade. Estas ações internas também são importantes. $\mathrm{O}$ aproveitamento racional das jazidas - que inclui a sua correta avaliação, $\mathrm{o}$ controle dos impactos e a recuperação das áreas degradadas - é fundamental para o 
melhor aproveitamento dos recursos e a integração da mineração com os outros usos do solo e com os outros setores de atividade econômica na busca da sustentabilidade.

Como chegar a isto ?

Em pronunciamento de 1997, um membro do segundo escalão do governo federal resumiu magistralmente a situação atual: não há uma política econômica, conseqüentemente não há uma política mineral. O que se necessita é uma inversão total desta situação.

É necessário haver vontade política, no mais alto nível, para destinar recursos para o levantamento das condições da mineração brasileira e para o planejamento concreto de seu desenvolvimento, seguidos de medidas para implantação das diretrizes definidas. Esta vontade política atualmente não existe. Tanto o executivo quanto o legislativo mostram total desprezo pela produção mineral, expresso na prática pela desastrosa privatização da Companhia Vale do Rio Doce e pela negação de recursos para os órgãos de pesquisa e controle minerário. É necessário um esforço de todos os componentes do setor mineral para demonstrar a importância da mineração e de suas áreas associadas, como as de pesquisa geológica e conservação ambiental. Demonstração que só será conseguida se for quebrado o isolamento entre o setor mineral e a sociedade. A crônica de comunicação do setor mineral é extremamente negativa. A mineração é considerada por órgãos ambientais, ONGs e população em geral como altamente poluidora, sem que seja reconhecido seu papel como uma das bases mais importantes da atividade humana. Nos Anuários e Sumários Minerais anteriormente elaborados pelo DNPM sempre constou a importância econômica das atividades dependentes do setor mineral, cerca de um terço do PIB. Nos atuais, nem isso consta mais.

Quando existe a vontade política os resultados são imediatos. Para demonstrálo basta verificar a história recente do setor mineral brasileiro. Quando foram feitos trabalho decidido de organização do setor e algum investimento - como no I Plano Mestre Decenal para Avaliação de Recursos Minerais do Brasil (1965-1975) houve resposta imediata, representada por descoberta de jazidas e atração de investimentos para o setor, seguidas pelo aumento da produção (Machado, 1989). Planos vazios, sem medidas administrativas adequadas nem financiamento - como o II Plano Mestre Decenal ou o Plano Plurianual para o Desenvolvimento do Setor Mineral (Brasil, 1995) - não contribuem para a melhoria da produção mineral.

Mesmo sem uma reorganização total do setor, algumas medidas concretas são necessárias e possíveis:

- a racionalização da legislação e de seu controle, permitindo ao minerador saber o que deve fazer com relação ao patrimônio mineral e ao meio ambiente, e facilitando sua legalização, sob a orientação de profissionais habilitados dos órgãos de controle, que também tenham respaldo para ações de fiscalização eficientes; 
- o estabelecimento de incentivos fiscais para a atividade minerária, compensando as desvantagens com relação a outros investimentos, como a maturação a longo prazo e o risco, que é alto para os minérios de baixo teor;

- a inserção da mineração como uso legítimo do solo nos planos diretores municipais após o estudo da potencialidade mineral do território. Sem este planejamento, a mineração não controlada destrói áreas necessárias para outras atividades, ao mesmo tempo em que áreas com alto potencial mineral são inviabilizadas por usos permanentes, principalmente aquelas com jazidas de bens de uso imediato em construção civil, de baixo valor e grande volume, que necessitam ser lavrados próximo à aplicação. É possível o uso seqüencial do solo, sendo a mineração uma atividade temporária, seguida por outra (habitacional, industrial ou de lazer) após o encerramento da mina e a sua recuperação final. Para tanto é necessária a negociação entre os diversos interessados, para harmonização entre as atividades e otimização do uso do solo.

A Universidade tem algumas funções importantes a desempenhar para o desenvolvimento do setor mineral e algumas são suas prerrogativas. Ela deve efetuar pesquisas, tanto em conjunto com instituições públicas e privadas quanto isoladamente, neste caso as mais valiosas por sua independência, o que não quer dizer que devam se afastar da realidade. A Universidade pode prestar serviços e consultorias aos participantes do setor mineral, desde que não torne esta prestação de serviços sua atividade principal, e não permita que a dependência de contratos para sua manutenção a torne um apêndice acrítico do governo ou das empresas. Mas é a formação de pessoal a sua principal e intransferível atribuição.

O autor identificou três atitudes na atuação dos profissionais de meio ambiente (Macedo, 1997a):

- a do conbecimento da natureza: procura dos dados básicos sobre a Terra e de seu inter-relacionamento, sem fim econômico imediato;

- a do domínio da natureza: aplicação dos conhecimentos para o aproveitamento dos recursos da Terra;

- a da integração com a natureza: com o conhecimento apoiando os esforços para a manutenção da humanidade na Terra em bases sustentáveis.

Conforme o momento histórico cada uma destas atitudes é privilegiada. Os gregos valorizavam o conhecimento, a revolução industrial exigia o domínio; suas conseqüências obrigam à integração com a natureza, sob pena da destruição da humanidade. Não é suficiente agora formar um cientista ou um técnico, embora tais aspectos devam estar desenvolvidos no profissional do meio ambiente. É fundamental desenvolver no futuro profissional uma atitude de respeito aos seres hu- 
manos e aos outros seres animados e inanimados. A melhor maneira de desenvolver essa consciência planetária (Ecológica? Holística? Integrada?) é o envolvimento do aluno, tão cedo quanto possível, em ações de defesa, aproveitamento racional e recuperação do meio ambiente.

O profissional da mineração (geólogo, engenheiro de minas) não pode ser apenas técnico. Deve ser um profissional do meio ambiente, e a obrigação da Universidade é ajudá-lo a desenvolver sua consciência planetária. Ao mesmo tempo, deve contribuir para desenvolver sua consciência política, habilitando-o a defender suas idéias. Quando se espera que haja uma vontade política para tomar medidas para o desenvolvimento da mineração em bases sustentáveis não se pode apenas desejar que ela se desenvolva espontaneamente no governo. Os profissionais conscientes devem atuar para que se difunda a compreensão da importância da mineração racional. É necessário que se rompa o isolamento que a mineração e a Geologia têm mantido do conjunto da população. A população conscientizada terá condições de reivindicar uma produção mineral que atenda às suas necessidades sem destruir o meio ambiente. Esta é a condição fundamental, embora não suficiente, para que haja mudança nas atitudes da administração e do setor produtivo com relação à mineração.

Referências bibliográficas

BAUERMEISTER, K.H. Distribuição e disponibilidade das áreas de areia para a construção civil, visando o abastecimento da região metropolitana de São Paulo. São Paulo, 1996. Dissertação (Mestrado), Instituto Geográfico da Universidade de São Paulo. $109 \mathrm{p}$.

BRASIL. MME-DNPM. Anuário Mineral 1996. Brasília, DNPM (arquivos da Internet, endereço http://www.dnpm.gov.br, sem paginação), 1996.

Plano Plurianual para o Desenvolvimento do Setor Mineral. Brasília, DNPM, s.p.(arquivo na Internet), 1995.

Sumário Mineral 1996. Brasília, DNPM, 1996. 104 p.

Sumário Mineral 1997. Brasília, DNPM, 1997. 189 p.

CASADEI, D.S., DEBIAZZI NETO, D. \& CHAVES, A.P. Aproveitamento de areia como produto do desassoreamento do rio Tietê. VII CONGRESSO BRASILEIRO DE MINERAÇÃO, 1997, s/p.

DALY, H.E. Sustainable growth research and exploration. National Geographic Society, v. 7, n. $4, \mathrm{~s} / \mathrm{p}$., apud LEMONS, J.F. \& BERRY, D. Sustainability in a materials society. Nonrenewable Resources, v. 5, n. 4, p. 277-284.

FRANCISCONI, Ó.; THEODOROVICZ, A.M. de G. \& CHIEREGATI, L.A.. Conteúdo e representação cartográfica para mapa do potencial mineral para não-metálicos. In: WORKSHOP: RECURSOS MINERAIS NÃO-METÁLICOS PARA O ESTADO DE SÃO PAULO. Resumos Expandidos, 1994, p. 23-26. 
MACEDO, A.B. Case studies of excessive legal and administrative constrainsts to mining in the USA and Brazil. FIRST INTERNATIONAL SYMPOSIUM ON MINING AND Development. Proceedings. Campinas, Unicamp, 1995, p. 185-191.

Recursos minerais e desenvolvimento sustentável. SEMINÁRIO CIÊNCIA E DESENVOLVIMENTO SUSTENTÁVEL. São Paulo, IEA-USP, 1997a, p. 130132.

Panorama da degradação da terra no Brasil. In: REBOUÇAS. A. Panoramas da degradação do ar, da água doce e da terra no Brasil. São Paulo, IEAUSP/CNPq, 1997b, p. 114-151.

MACEDO, A.B.; ANTONINI, S.A.; PINTO, G.G.; ALEGRI, V. \& LOUREIRO, O. Projeto seleção de áreas para a mineração de areia na região metropolitana de São Paulo. São Paulo, SICCT-Pró-Minério/CPRM, 1986, 250 p.

MACEDO, A.B.; BORDIGNON, J.L.; VALVERDE, F.M.; OSTAFIUC, G.B.; NATIVIDADE, H.; ANTONINI, S.A.; SILVA, H.V. \& COIMBRA, A.M. A mineração de areia na região metropolitana de São Paulo: aspectos econômicos, geológicos e ambientais. $5^{\circ}$ SIMPÓSIO REGIONAL DE GEOLOGIA, São Paulo, SBG. Atas, 1985, n. 1, p. $79-88$.

MACEDO, A.B.; MANTOVANI, W. \& BRIGHETTI, G. Parecer técnico sobre o processo n. 2766/89 da Comarca de Santos. Ação Civil Pública Ambiental movida pela Equipe Regional de Proteção ao Meio Ambiente da Baixada Santista, contra a Lello Empreendimentos Imobiliários Ltda. São Paulo, IG-USP/CEPA, 1997, 14 p., mapas, fotos [inédito].

MACHADO, I. Recursos minerais - politica e sociedade. São Paulo, Pró-Minério/ Edgard Blücher, 1989. 410 p.

MARTINS, L.A.M. (adap.) Os recursos físicos da terra - Bloco 2 - Materiais de construção e outras matérias brutas. Campinas, Unicamp/Open University, 1995. 89 p.

OKAGAWA, H.; SANTOS, A.R. dos \& SILVA, R.B. da. Estudo de métodos de lavra de areia e de processos de reabilitação de áreas mineradas (RMSP) - Fase I. Relatório IPT $\mathrm{n}^{\mathrm{o}}$ 24.644. $57 \mathrm{p}$.

RESUMO - OS RECURSOS minerais não-metálicos, embora muito importantes para o atendimento das necessidades da população e para o comércio exterior, são pouco contemplados pelas ações governamentais e ignorados pelo público. Geralmente não-incluída no planejamento territorial, a mineração de não-metálicos no Brasil causa extensos impactos ambientais mal controlados. Propõe-se uma ação coordenada de fomento e controle patrimonial e ambiental da mineração, que só será conseguida por ação política, a qual depende da formação abrangente dos profissionais da mineração e de sua maior comunicação com a totalidade da população.

ABSTRACT - NONMETALLIC mineral resources, albeit very important for the needs of the population and for exportation, are ill-favored by governmental actions and ignored by the public. Generally not included in territorial planning, the mining of nonmetallic 
minerals in Brazil produces extensive, ill-controlled environmental impacts. A coordinated action of promotion and control, both patrimonial and environmental of mining, is proposed. This will only be achieved by political action, which depends on a more comprehensive education of mining professionals and on a greater communication by them with the population as a whole.

Arlei Benedito Macedo é professor do Instituto de Geociências da Universidade de São Paulo 